\title{
Suggestion for the Proper Treatment of Buoyancy Force Effect on Single Phase Thermal Stratification Phenomenon
}

\author{
Gong-Hee Lee ${ }^{1,2^{*}}$ \\ ${ }^{1}$ Korea Institute of Nuclear Safety, Regulatory Assessment Department, 34142 Daejeon, Korea \\ ${ }^{2}$ University of Science and Technology, Nuclear and Radiation Safety Department, 34113 Daejeon, Korea
}

\begin{abstract}
In the operating nuclear power plant, piping and components installed in the in-service testing (IST) systems connected to the reactor coolant system are potentially exposed to fatigue caused by thermal stratification flow, possibly threatening its integrity. The emergency core cooling system (ECCS) is one of candidates for which the thermal stratification phenomenon can occur. During the ECCS operating period, buoyancy due to density difference may have significant influence on thermal-hydraulic characteristics of the mixing flow. Therefore, in this study, the need to consider proper buoyancy models in governing equations, especially turbulent transport equations, for accurate prediction of single phase thermal stratification by ECCS injection was numerically studied using ANSYS CFX R17.2.
\end{abstract}

\section{Introduction}

Nuclear power plant operators conduct in-service testing (IST) to verify the safety functions of safety-related pumps and valves, and to monitor the degree of vulnerability over time during reactor operation [1]. Piping and components installed in the IST-related systems connected to the reactor coolant system are potentially exposed to fatigue caused by thermal stratification flow, possibly threatening its integrity.

Numerical analysis using different computer fluid dynamics (CFD) software has been performed to assess the effect of the emergency core coolant injection on single-phase flow mixing in the cold leg [2-4]. However, there was a significant difference between the predicted and the measured fluid temperature data at several measurement locations.

In this study, effect of buoyancy turbulence option, available in ANSYS CFX R17.2, on the prediction accuracy for single phase thermal stratification in the cold leg and downcomer was examined.

\section{Analysis model}

The Japan Atomic Energy Agency (JAEA) manufactured ROSA (Rig Of Safety Assessment)-LSTF (Large Scale Test Facility) to investigate the thermal hydraulic behavior during pressurized water reactor transients and accidents (for example, small break loss of coolant accident). The objective of Test 1 is to clarify the phenomenon of temperature stratification on the cold legs and the upper region of downcomer of the reactor vessel, which are important for the evaluation of the pressurized thermal shock (PTS) during the coolant injection by the ECCS, and to obtain the measured data for the main parameters with the aim of validating the simulation code and the numerical modeling. Fig. 1 shows the schematic diagram of the analysis model. An inner diameter of the cold leg was $207 \mathrm{~mm}$. The radial gap size of the annular downcomer between the inner and outer walls of the reactor vessel was $46 \mathrm{~mm}$.

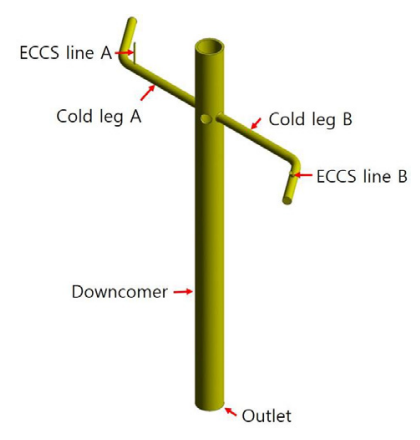

Fig. 1. Schematic diagram of the analysis model.

As shown in Fig. 2, to investigate the thermal stratification phenomenon in the cold leg A, 21 thermocouples were installed in 3 columns and 7 rows at two cross-sections (TE2, TE3) in the cold leg A between the ECCS line A and the downcomer. On the other hand, 18 thermocouples were installed in the downcomer. The nominal accuracy of the thermocouple measurements was $\pm 2.75 \mathrm{~K}$.

The primary and secondary pressures under single-phase natural circulation operating conditions were $15.5 \mathrm{MPa}$ and $6.7 \mathrm{MPa}$, respectively. In this study, the measured data at intervals of $2.5 \mathrm{~s}$ were compared with the calculated results for the cases which the cold coolant was injected through the ECCS line A during time intervals of $18 \mathrm{~s} \sim 100 \mathrm{~s}$ under the natural circulation condition after the main coolant pump stopped.

\footnotetext{
* Corresponding author: ghlee@kins.re.kr
} 


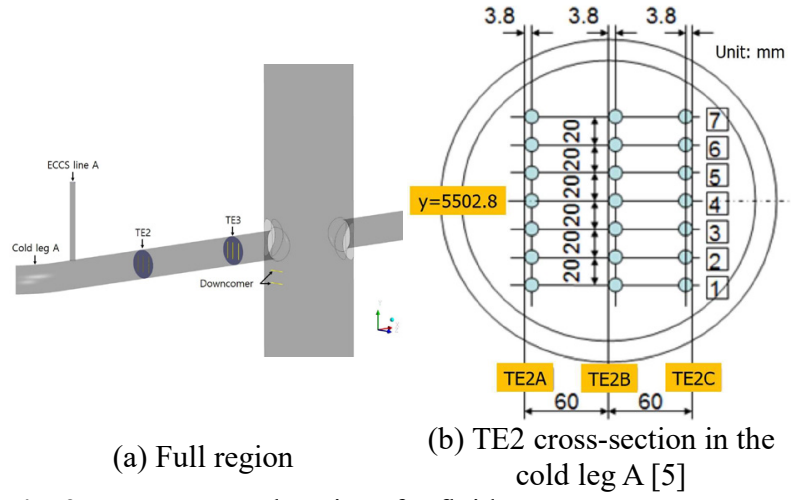

Fig. 2. Measurement locations for fluid temperature.

\section{Numerical modeling}

In this study, the turbulent flow field inside the ROSALSTF was calculated under unsteady, single-phase, incompressible and non-isothermal conditions by using the commercial CFD software, ANSYS CFX R17.2. High resolution scheme with quasi-second-order accuracy was used for the convection-terms-of-momentum and turbulence equations. The second order backward Euler option was used as the time discretization scheme. Calculation with time step $\Delta \mathrm{t}=0.1 \mathrm{~s}$ was performed from $\mathrm{t}=0 \mathrm{~s}$ to $200 \mathrm{~s}$. It was determined that the solution was converged when the root mean square residuals of the individual equations were $10^{-5}$ or less at each time step. On the other hand, the temperature-dependent density, dynamic viscosity and conductivity of the working fluid, water, were taken into account by using the IAPWS-IF97 table available in ANSYS CFX R17.2.

In author's previous study [6], it was confirmed that the fluid/wall temperature distributions were differently predicted in the cold leg and downcomer; depending on the Reynolds averaged Navier-Stokes (RANS) based turbulence models. In this study, the turbulent thermal stratification flow inside the ROSA-LSTF was calculated using the Baseline Reynolds Stress model among the turbulence models based on the RANS equation available in ANSYS CFX R17.2.

To accurately simulate the thermal stratification phenomenon using CFD software, it is necessary to add the appropriate buoyancy term model to governing equations such as the momentum and turbulent transport equations $[7,8]$. In this study, to investigate the effect of choosing buoyancy turbulence option on single phase thermal stratification by the ECCS injection, three options available in ANSYS CFX R17.2 were considered, as shown in Table 1. For all cases, the buoyancy-related source term was considered in the momentum equation by default. For option 1, the effect of buoyancy was not considered in the turbulence transport equations. In case of option 2, Production option was only considered.

Table 1. Buoyancy turbulence options in ANSYS CFX R17.2.

\begin{tabular}{|l|c|c|c|}
\hline & option 1 & option 2 & option 3 \\
\hline Production & OFF & ON & ON \\
\hline Dissipation & OFF & ON & ON \\
\hline
\end{tabular}

For option 3, Production and Dissipation option was applied. More detailed descriptions of the buoyancy turbulence option can be found in the ANSYS CFXSolver theory guide [9].

Hexahedral grid system was generated by using ICEMCFD software for the computational domain that had the same size as the test facility. In this study, grid refinement study was performed for three types of grid systems as shown in Table 2 and type B grid was finally used by considering the computational time, the prediction accuracy etc.

Table 2. Grid information.

\begin{tabular}{|l|c|c|c|}
\hline \multicolumn{1}{|c|}{ Items } & type A & type B & type C \\
\hline Total elements & $8.92 \times 10^{5}$ & $1.99 \times 10^{6}$ & $4.93 \times 10^{6}$ \\
\hline Min. face angle & $16.4^{\circ}$ & $15.9^{\circ}$ & $15.6^{\circ}$ \\
\hline Max. face angle & $164.7^{\circ}$ & $165.6^{\circ}$ & $165.9^{\circ}$ \\
\hline Max. edge length ratio & 116.9 & 102.5 & 104.2 \\
\hline Max. element volume ratio & 13.1 & 15.3 & 12.7 \\
\hline
\end{tabular}

The measured unsteady flow rate and temperature were applied at inlet of the cold leg A/B and the ECCS injection line $\mathrm{A}$. In addition, turbulence intensity at each inlet was assumed to be $5.0 \%$. The average static pressure condition was applied at the outlet. No-slip and adiabatic conditions were applied at all wall surfaces including the pressure vessel. To model the flow in the near-wall region, automatic wall treatment was applied.

\section{Result and discussion}

Fig. 3 show the fluid temperature distribution at the TE2 and TE 3 cross-sections in the cold leg A for $t=40 \mathrm{~s}$. For the fluid temperature distribution in the corresponding cross-sections, both option 1 and 3 predicted the fluid temperature gradient to be larger than option 2 .

To evaluate the reliability of the predicted fluid temperature at the measurement locations of the cold leg A using ANSYS CFX R17.2, the predicted results were compared with the measured data using Equation (1) and the reliability scores were calculated.

$$
\text { Score }=\frac{1}{N} \sum_{i=1, N}\left|\operatorname{Temp}_{\text {comp }, i}-\operatorname{Temp}_{\text {exp }, i}\right|
$$

where $N$ is the number of test data at each measurement location, Temp $p_{\text {comp }, i}$ is the predicted temperature from the CFD calculation, and Temp $p_{\text {exp }, i}$ is the measured fluid temperature at the same location. Note that the lower the reliability score, the better the predicted results are in good agreement with the measured data.

Fig. 4 is a histogram of the reliability scores of fluid temperature calculated from the measurement locations in the cold leg A. At TE2 cross-section, in which the lowtemperature ECC water and the high-temperature cold leg coolant were strongly mixed, option 2 showed the best prediction performance. 


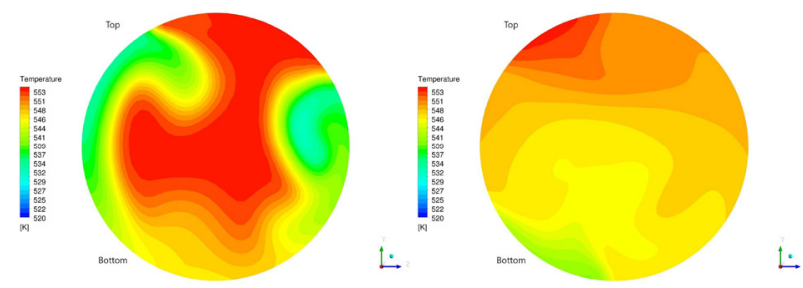

(a) option 1

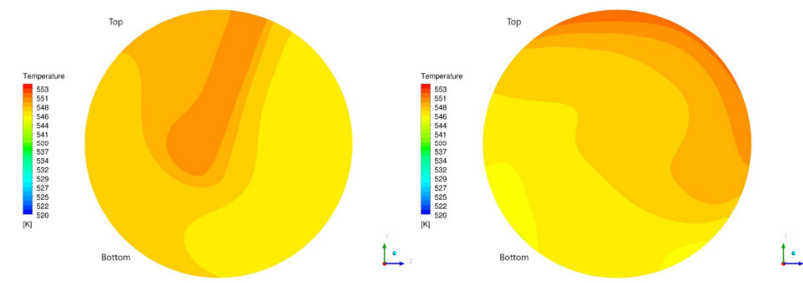

(b) option 2

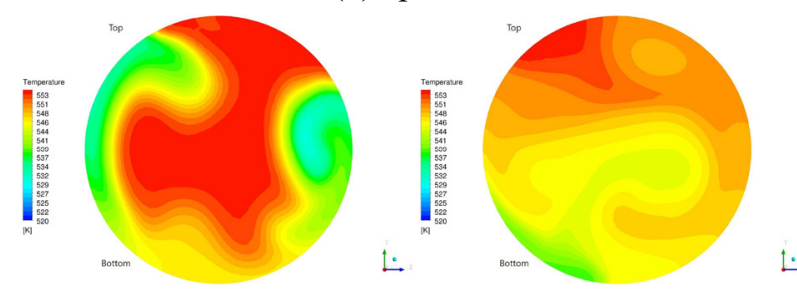

(c) option 3

Fig. 3. Fluid temperature distribution at the TE2 (left) and TE3 (right) cross-sections in the cold leg A $(t=40 \mathrm{~s})$.

In summary, it has been confirmed that the fluid/wall temperature distributions were predicted differently in the cold leg on the buoyancy turbulence options available in ANSYS CFX R17.2. Therefore, licensing applicant using ANSYS CFX should carefully choose the buoyance turbulence options to obtain the physically reasonable and accurate result. Also, it is necessary for a nuclear regulator to confirm whether buoyancy terms, which are properly modeled, are considered in the turbulent transport equations for CFD software used by licensing applicant.

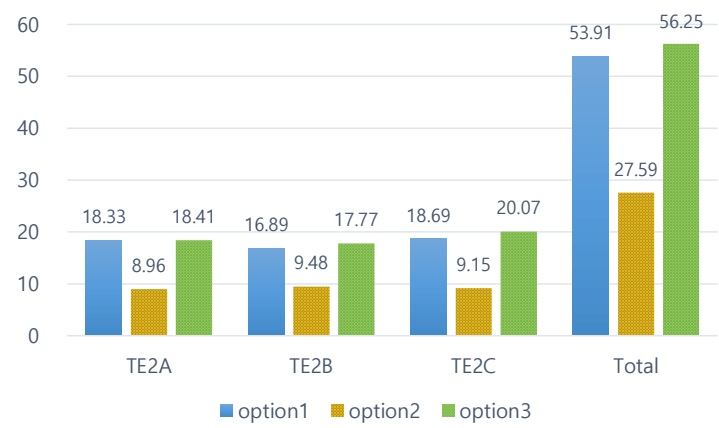

Fig. 4. Reliability scores of fluid temperature calculated at the measurement locations in the cold leg A.

This work was supported by the Nuclear Safety Research Program through the Korea Foundation Of Nuclear Safety (KOFONS) using the financial resource granted by the Nuclear Safety and Security Commission (NSSC) of the Republic of Korea (No. 1805007). This work was also supported by the Supercomputing Center/Korea Institute of Science and Technology Information with supercomputing resources including technical support (project number: KSC-2018-CRE-
0076). Finally, this paper was written by using the experimental data from OECD/NEA ROSA Project (CSNI2009/01).

\section{References}

1. G.H. Lee, J.H. Bae, 15th Asian International Conference on Fluid Machinery, AICFM15-091 (2019)

2. M. Scheuerer, J. Weis, Nuclear Eng. \& Design 253, (2012)

3. J. Cai, T. Watanabe, Prog. Nuclear Science \& Tech. 2, (2011)

4. T. Farkas, I. Toth, Nuclear Eng. \& Design 240, (2010)

5. Japan Atomic Energy Agency, Final Data Report of OECD/NEA ROSA Project Test 1-1, (2008)

6. G.H. Lee, Nuclear Safety Technology Analysis Report, NSTAR-19NS13-74, (2019)

7. G.H. Lee, A.J. Cheong, Trans. Korean Nuclear Society Autumn Meeting, (2017)

8. G.H. Lee, Y.S. Bang, S.W. Woo, Trans. Korean Soc. Mech. Eng. B 36, (2012)

9. ANSYS Inc., ANSYS CFX-Solver theory guide, (2016) 